\title{
Modeling and Control of a Doubly-Fed Induction Generator (DFIG) Wind Power Generation System for Real-time Simulations
}

\author{
Gilsung Byeon*, In Kwon Park** and Gilsoo Jang ${ }^{\dagger}$
}

\begin{abstract}
This paper presents a study of a DFIG wind power generation system for real-time simulations. For real-time simulations, the Real-Time Digital Simulator (RTDS) and its user friendly interface simulation software RSCAD are used. A 2.2MW grid-connected variable speed DFIG wind power generation system is modeled and analyzed in this study. The stator-flux oriented vector control scheme is applied to the stator/rotor side converter control, and the back-to-back PWM converters are implemented for the decoupled control. The real-wind speed signal extracted by an anemometer is used for a realistic, reliable and accurate simulation analysis. Block diagrams, a mathematical presentation of the DFIG and a control scheme of the stator/rotor-side are introduced. Real-time simulation cases are carried out and analyzed for the validity of this work.
\end{abstract}

Keywords: Doubly-fed induction generator, Wind power generator, Real time simulation, RTDS/ RSCAD

\section{Nomenclature}

$\rho:$ derivative symbol

$v_{d s}, v_{q s}:$ stator voltages in $\mathrm{d}-\mathrm{q}$ axis reference frame

$v_{d r}, v_{q r}:$ rotor voltages in $\mathrm{d}-\mathrm{q}$ axis reference frame

$i_{d s}, i_{q s}:$ stator currents in d-q axis reference frame

$i_{d r}, i_{q r}:$ rotor currents in $\mathrm{d}-\mathrm{q}$ axis reference frame

$\varphi_{d s}, \varphi_{q s}:$ stator flux linkages in d-q axis reference frame

$\varphi_{d r}, \varphi_{q r}:$ rotor flux linkages in $\mathrm{d}-\mathrm{q}$ axis reference frame

$\alpha, \beta:$ alpha and beta axis reference frame symbol

$P_{s}, Q_{s}:$ stator active, reactive power

$P_{r}, Q_{r}$ : rotor active, reactive power

$R_{s}, R_{r}$ : stator and rotor resistance per phase

$\omega_{e}, \omega_{r}$ : supply and rotor flux angle

$\theta_{e}, \theta_{r}$ : supply and rotor angular frequency

$L_{s}, L_{r}:$ stator and rotor inductance

$L_{l s}, L_{l r}, L_{m}:$ stator, rotor leakage inductance, and magnetizing inductance

$T_{e}$ : electromagnetic torque

$P$ : number of poles

$E$ : DC-link voltage

$\sigma$ : leakage factor

$M_{1}, M_{2}:$ stator and rotor modulation depths

$i_{o s}, i_{o r}:$ stator and rotor converter DC-link current

Corresponding Author: Corresponding Author: School of Electrical Engineering, Korea University, Korea. (gjang@korea.ac.kr)

* School of Electrical Engineering, Korea University, Korea. (bgsean@korea.ac.kr)

** RTDS Technologies Inc, Canada. (parkik@rtds.com)

Received : June 11, 2009; Accepted : January 9, 2010

\section{Introduction}

Among the various renewable energy sources, wind energy is one of the most important energy sources in power systems. Wind power generation systems are already popular in Europe, and the utilization of this renewable energy source is expanding rapidly to other areas of the world [1][3]. Because of its attractive advantages, including zero$\mathrm{CO}_{2}$ emissions, high efficiency and low operation cost, the penetration of wind power generation systems is increasing in spite of the variable characteristics of wind speed. Wind power generation system technology is developing very quickly, which has resulted in the development of many new modeling and simulation methods.

The Doubly-Fed Induction Generator (DFIG) concept has become one of the most favorable options in modern wind power market. The DFIG consists of a Wounded Rotor Induction Generator (WRIG) with the stator windings directly connected to the constant frequency three-phase grid and with the rotor winding connected to a bidirectional back-to-back PWM voltage Source Converter (VSC).

Over the past three decades, various DFIG modeling methods have been introduced. W. Leonhard first suggested a vector control scheme for decoupled control of torque and rotor current [4], and S. R. Jones and R. Jones used a sinusoidal supply side converter and proposed its control scheme [5]. R. Pena later designed a DFIG structure with a Scherbius scheme, consisting of two back-toback PWM converters [6]-[8]. In these papers, the statorflux oriented vector control method for two converters control, the control schemes of a slip-ring DFIG which was connected to grid systems and supplying an isolated load at constant voltage and frequency were presented.

Using a more detailed approach, where a grid-connected DFIG which has been implemented by S. K. Salman and B. 
Badrzadeh [9], a decoupled design based on Internal Model Control (IMC) to set synchronous vector controllers has been introduced. To observe the rotor position and speed of a DFIG, a stator-flux based model reference adaptive system (MRAS) structure is considered [10], [11]. The MRAS observer predicts the rotor position estimation errors under parameter mismatch.

In recent years, a new converter scheme has been applied to the DFIG system, and is referred to as a matrix converter. The matrix converter has been investigated in the last two decades. The commutation time has been minimized to avoid any unnecessary waveform distortion, particularly at low demanded output voltages. This advantage gives the matrix converter superior waveform quality in comparison to conventional converters [12]-[16].

The RTDS is the EMTP based simulator that enables real-time inputs, and simulation result outputs of the RSCAD. The real-time simulator can support more realistic, accurate and reliable analysis [17]. In particular, real-time simulators are preferable to other typical simulation programs in protection and renewable energy source simulations [18]. In this paper, a DFIG wind power generation system is implemented, but switching dynamics in the converter are neglected.

The real time simulation of a wind power generation system was performed using Real-Time Digital Simulator (RTDS) [19], [20]. In these papers, a 3MW fixed speed squirrel cage wind generator system is connected to the power grid and is modeled using user friendly interface simulation software, RSCAD. Since the fixed-speed rotor concept has been implemented in these papers, the rotor speed and active power are not changed by wind speed fluctuation.

In this paper, a 2.2MW variable speed DFIG wind power generation system is implemented and investigated using RTDS/RSCAD. To observe the response of DFIG to realwind speed input, the modified voltage signal extracted by a real anemometer is connected to the RTDS and utilized for real-time simulation. A stator-flux oriented vector control scheme is applied in the control scheme, and back-toback PWM voltage source converters are modeled for the decoupled control [21]. For the validity of this work, power, voltage, current, pitch, rotor speed plots in simulation are shown and analyzed.

\section{Control of Induction Generator and Converters}

\subsection{Basic Structure of the DFIG Wind Power Genera- tion System}

The term 'doubly fed' refers to the fact that the voltage on the stator is applied from the grid and the voltage on the rotor is induced by the rotor-side converter. This system allows a variable-speed operation over a large, but restricted, range. The converter compensates the difference between the mechanical and electrical frequency by injecting a rotor current with a variable frequency. The behavior of the DFIG is controlled by the converter and its controller in both normal and fault condition operation [2].

Fig. 1 shows the basic structure of the DFIG wind power generation system. Back-to-back PWM converters consist of two converters, the stator-side converter and rotor-side converter, which are controlled independently of each other. The main idea is that the rotor-side converter controls the active and reactive power by controlling the rotor current components, while the stator-side converter controls the DC-link voltages and ensures a converter operation at unity power factor (zero reactive power).

Depending on the operating condition of the rotor, the power is fed into or out of the rotor. In an oversynchronous condition, power flows from the rotor via the converter to the grid, whereas power flows in the opposite direction in a sub-synchronous condition. In both cases, the stator feeds power into the grid [9].

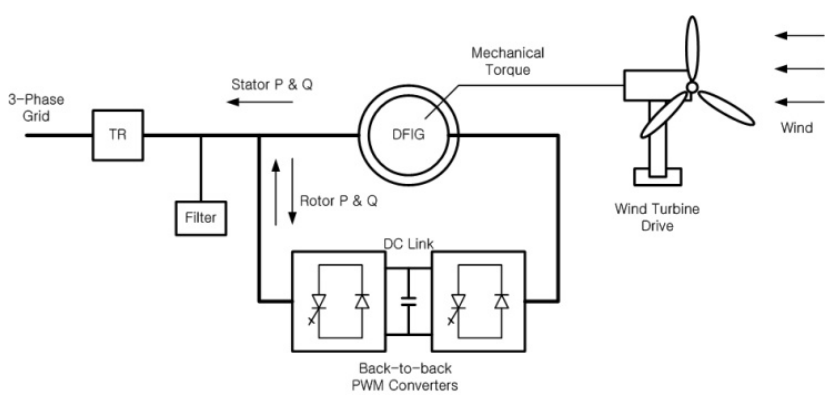

Fig. 1. Structure of DFIG wind power generation system.

\subsection{Generator Model for Wounded Rotor Induction Generator}

A DFIG consists of a WRIG with the stator, and rotor windings. Generally, the model of the WRIG in an EMTP simulation is the same as any fixed-speed induction generator, such as the squirrel cage induction generator.

The stator and rotor voltage equations of a wounded rotor induction generator in the $\mathrm{d}-\mathrm{q}$ reference frame are as follows [22], [23]:

$$
\begin{gathered}
v_{d s}=R_{s} i_{d s}-\omega_{e} \varphi_{q s}+\rho \varphi_{d s} \\
v_{q s}=R_{s} i_{q s}-\omega_{e} \varphi_{d s}+\rho \varphi_{q s} \\
v_{d r}=R_{r} i_{d r}-\left(\omega_{e}-\omega_{r}\right) \varphi_{q r}+\rho \varphi_{d r} \\
v_{q r}=R_{r} i_{q r}+\left(\omega_{e}-\omega_{r}\right) \varphi_{d r}+\rho \varphi_{q r}
\end{gathered}
$$

The instantaneous power input of the stator in the $d-q$ reference frame is

$$
\begin{gathered}
P_{s}=\frac{3}{2}\left(v_{d s} i_{d s}+v_{q s} i_{q s}\right) \\
Q_{s}=\frac{3}{2}\left(v_{q s} i_{d s}-v_{d s} i_{q s}\right)
\end{gathered}
$$

The electromagnetic torque of the WRIG is obtained by the power associated with the speed voltage divided by the 
turbine shaft speed in mechanical radians per second. From Equations (3), (4), the speed voltage terms related with $v_{d s}$ and $v_{q s}$ are $-\omega_{e} \varphi_{q s}$ and $\omega_{e} \varphi_{d s}$. Substituting Equations (5), (7), the power equation of the stator related with speed voltage is [22]

$$
P_{s}=-\frac{3}{2} \omega_{e}\left(\varphi_{q s} i_{d s}-\varphi_{d s} i_{q s}\right)
$$

Similarly, the power equation of the rotor associated with speed voltage is

$$
P_{r}=-\frac{3}{2}\left(\omega_{e}-\omega_{r}\right)\left(\varphi_{q r} i_{d r}-\varphi_{d r} i_{q r}\right)
$$

The rotor speed with respect to d-q axis reference frame is $-\left(\omega_{e}-\omega_{r}\right) \frac{2}{P}$. So the electromagnetic torque is

$$
T_{e}=\frac{3}{4} P\left(\varphi_{q r} i_{d r}-\varphi_{d r} i_{q r}\right)
$$

The flux linkages in Equations (1-4) can be calculated by using following equations:

$$
\begin{aligned}
& \varphi_{d s}=\left(L_{l s}+L_{m}\right) i_{d s}+L_{m} i_{d r}=L_{s} i_{d s}+L_{m} i_{d r} \\
& \varphi_{q s}=\left(L_{l s}+L_{m}\right) i_{q s}+L_{m} i_{q r}=L_{s} i_{q s}+L_{m} i_{q r} \\
& \varphi_{d r}=\left(L_{l r}+L_{m}\right) i_{d r}+L_{m} i_{d s}=L_{r} i_{d r}+L_{m} i_{d s} \\
& \varphi_{q r}=\left(L_{l r}+L_{m}\right) i_{q r}+L_{m} i_{q s}=L_{r} i_{q r}+L_{m} i_{q s}
\end{aligned}
$$

The stator and rotor inductance is defined as follows:

$$
\begin{aligned}
& L_{s}=L_{l s}+L_{m} \\
& L_{r}=L_{l r}+L_{m}
\end{aligned}
$$

\subsection{Stator Control of DFIG}

In the stator-side converter control, the main purpose is to maintain the DC-link voltage constant regardless of the magnitude and direction of the rotor power. A stator-flux oriented vector control scheme enables decoupled control of active and reactive power flowing between the threephase grid and the stator-side converter. A currentregulated PWM scheme is used, where the d-q reference frame currents are used to regulate DC-link voltage and reactive power [7].

Fig. 2 shows the schematic structure of the stator-side converter. Considering the relationship of the inductance and resistance in Fig. 2, voltage equations across the inductor can be written as follows [9]:

$$
\left[\begin{array}{l}
v_{a s} \\
v_{b s} \\
v_{c s}
\end{array}\right]=R\left[\begin{array}{l}
i_{a s} \\
i_{b s} \\
i_{c s}
\end{array}\right]+L \rho\left[\begin{array}{l}
i_{a s} \\
i_{b s} \\
i_{c s}
\end{array}\right]+\left[\begin{array}{c}
v_{a 1} \\
v_{b 1} \\
v_{c 1}
\end{array}\right]
$$

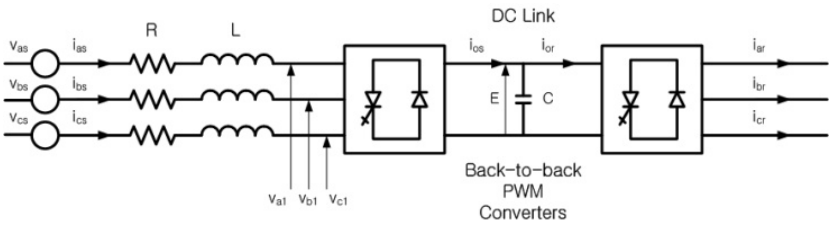

Fig. 2. Structure of Connection between Grid and Back-toback Converters.

Using the phase and rotation transformations to Equation (18) results in [23]

$$
\begin{aligned}
& v_{d s}=R i_{d s}+L \rho i_{d s}-\omega_{e} L i_{q s}+v_{d 1} \\
& v_{q s}=R i_{q s}+L \rho i_{q s}+\omega_{e} L i_{d s}+v_{q 1}
\end{aligned}
$$

\subsection{Decoupled Control of Stator-side Converter}

The supply flux angle is calculated as

$$
\theta_{e}=\int \omega_{e} d t=\tan ^{-1} \frac{v_{\beta}}{v_{\alpha}}
$$

Aligning the $\mathrm{d}$-axis of the reference frame along the stator-voltage angle in eqn. (21), $v_{q s}=0$, and, since the amplitude of the supply voltage is constant, $v_{d s}$ is constant. So eqns. (5), (6) can be rewritten as follows:

$$
\begin{gathered}
P_{s}=\frac{3}{2} v_{d s} i_{d s} \\
Q_{s}=-\frac{3}{2} v_{d s} i_{q s}
\end{gathered}
$$

Neglecting harmonics due to the switching and the losses in the inductor resistance and converter, the voltage and current equations of the DC-link, ie. Equations (24-27), is from [7].

$$
\begin{gathered}
E i_{o s}=3 v_{d} i_{d} \\
v_{d}=\frac{m_{1}}{2 \sqrt{2}} E \\
i_{o s}=\frac{3}{2 \sqrt{2}} m_{1} i_{d} \\
C \frac{d E}{d t}=i_{o s}-i_{o r}
\end{gathered}
$$

From Equations (24-27), the DC-link voltage can be controlled by $i_{d}$. Therefore, reference values for the statorside converter can be written as

$$
\begin{gathered}
v_{d 1}^{*}=-v_{d}^{\prime}+\left(\omega_{s} L i_{q}+v_{d}\right)=-v_{d}^{\prime}+v_{d 1}^{\text {comp }} \\
v_{q 1}^{*}=-v_{q}^{\prime}+\left(\omega_{s} L i_{d}\right)=-v_{q}^{\prime}+v_{q 1}^{\text {comp }}
\end{gathered}
$$

In Equations (28), (29), $v_{d 1}^{\text {comp }}$ and $v_{q 1}^{\text {comp }}$ are voltage 
compensation terms. Therefore, it is possible to control d-q axis reference frame components of the stator-side converter independently.

Fig. 3 depicts a schematic diagram of the stator-flux oriented stator-side converter control. A direct rotor flux oriented system, with the rotor flux estimated from the terminal quantities, is sensitive to the variations in the leakage inductance of the machine because the estimation of rotor flux depends on the leakage inductance. Using the fact that the stator flux can be estimated from the terminal quantities is more accurate than the rotor flux [21]. The close-loop control scheme presented in Fig. 3 is to maintain the DClink voltage constant.

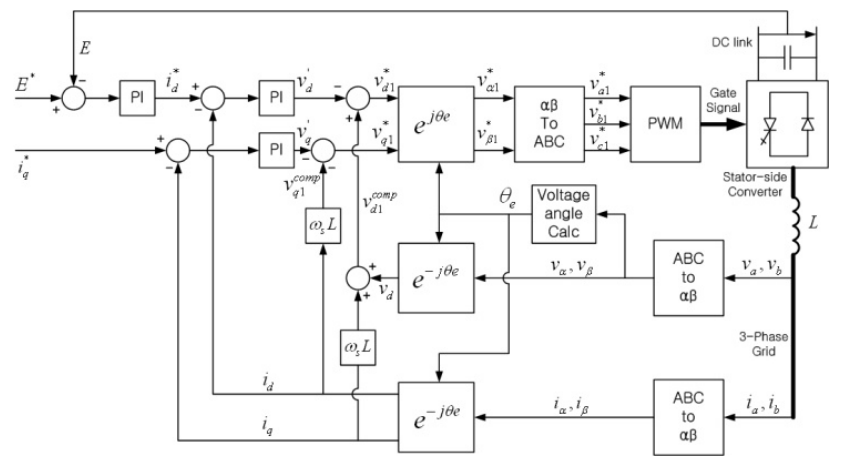

Fig. 3. Block Diagram of Stator-side Converter Control Scheme.

\subsection{Decoupled Control of DFIG}

The electromagnetic torque and the rotor excitation current can be controlled independently. The DFIG is controlled in synchronously d-q reference frame, with the daxis oriented along the stator-flux vector position. Since the control scheme can be presented along the stator-flux linkage, the q-axis flux component must be zero [9].

$$
\varphi_{q s}=0
$$

From Equation (13),

$$
i_{q s}=-\frac{L_{m}}{L_{l s}+L_{m}} i_{q r}
$$

Substituting for $i_{q s}$ into eqn. (11), torque equation is

$$
T_{e}=-\frac{3}{4} P \frac{L_{m}}{L_{l s}+L_{m}} \varphi_{d s} i_{q r}=-\frac{3}{4} P \frac{L_{m}}{L_{s}} \varphi_{d s} i_{q r}
$$

Since the stator is connected to the three-phase grid, the effect of stator resistance is very small and can be neglected. So the d-axis flux component $\varphi_{d s}$ is assumed to be constant [7]. Consequently, the electrical toque is controlled by $i_{q r}$.

Under stator-flux vector control, the voltages, currents and flux must be redefined for decoupled control. The following parameter called leakage factor of induction generator is defined in [23]:

$$
\sigma=1-\frac{L_{m}^{2}}{L_{s} L_{r}}=1-\frac{L_{m}^{2}}{\left(L_{l s}+L_{m}\right)\left(L_{l r}+L_{m}\right)}
$$

Substituting for $i_{d s}$ from Equation (12) into Equation (14), for $i_{q s}$ from Equation (31) into Equation (15), the flux equations of the rotor is

$$
\begin{gathered}
\varphi_{d r}=\sigma\left(L_{l r}+L_{m}\right) i_{d r}+\frac{L_{m}}{L_{l s}+L_{m}} \varphi_{d s}=\sigma L_{r} i_{d r}+\frac{L_{m}}{L_{s}} \varphi_{d s} \\
\varphi_{q r}=\sigma\left(L_{l r}+L_{m}\right) i_{q r}=\sigma L_{r} i_{q r}
\end{gathered}
$$

Substituting Equations (34), (35), into Equations (3), (4), the voltage equations of the rotor can be described as follows:

$$
\begin{gathered}
v_{d r}=v_{d r}^{\prime}+v_{d r}^{c o m p} \\
v_{q r}=v_{q r}^{\prime}+v_{q r}^{c o m p} \\
v_{d r}^{\prime}=R_{r} i_{d r}+\sigma\left(L_{l r}+L_{m}\right) \rho i_{d r} \\
v_{q r}^{\prime}=R_{r} i_{q r}+\sigma\left(L_{l r}+L_{m}\right) \rho i_{q r} \\
v_{d r}^{c o m p}=\frac{L_{m}}{L_{l s}+L_{m}} \rho \varphi_{d s}-\left(\omega_{e}-\omega_{r}\right) \sigma\left(L_{l r}+L_{m}\right) i_{q r} \\
v_{q r}^{c o m p}=\left(\omega_{e}-\omega_{r}\right) \frac{L_{m}}{L_{l s}+L_{m}} \varphi_{d s}-\left(\omega_{e}-\omega_{r}\right) \sigma\left(L_{l r}+L_{m}\right) i_{d r}
\end{gathered}
$$

The voltage-compensated terms $v_{d r}^{\text {comp }}$ and $v_{q r}^{\text {comp }}$ make it possible to achieve decoupled control of the stator-flux oriented control of the rotor-side converter. So each axis reference frame voltage of rotor can be controlled by using each axis reference frame current.

The stator flux angle is calculated using phase and rotation transformed stator currents and the rotor flux angle is calculated using rotor currents that pass through the encoder block.

$$
\begin{gathered}
\varphi_{\alpha s}=\int\left(v_{\alpha s}-R_{s} i_{\alpha s}\right) d t \\
\varphi_{\beta s}=\int\left(v_{\beta s}-R_{s} i_{\beta s}\right) d t \\
\theta_{s}=\tan ^{-1} \frac{\varphi_{\beta s}}{\varphi_{\alpha s}}
\end{gathered}
$$

Fig. 4 shows a schematic diagram of a stator-flux oriented

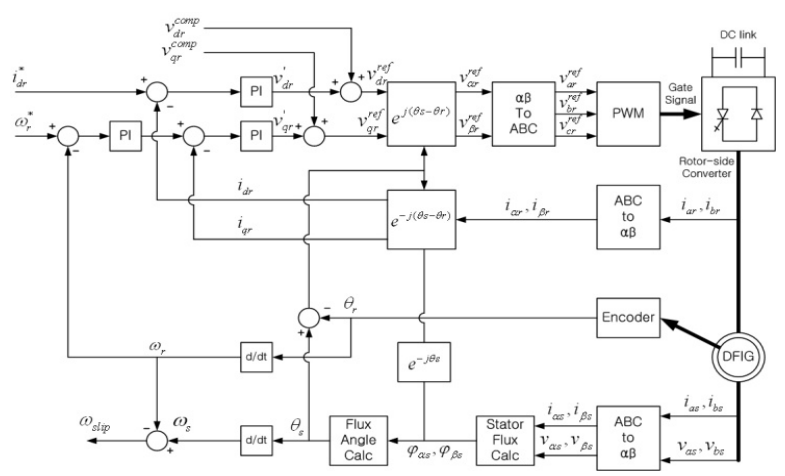

Fig. 4. Block Diagram of Rotor-side Converter Control Scheme. 
rotor-side converter control. In order to control rotor current components, PI controllers are applied. The stator and rotor flux angle extraction schemes are also represented in this diagram as well.

\subsection{Pitch Angle Controller Model}

The pitch angle controller is active only in wind speeds above the rated wind speed of the wind turbine drive. In such circumstances, the rotor speed can no longer be controlled by increasing the generated power, as this would lead to overloading the generator and converter. Therefore, the blade pitch angle is changed in order to limit the aerodynamic efficiency of the wind turbine. This control scheme prevents the rotor speed from becoming too high, which would result in mechanical damage [2].

It should be taken into account that the pitch angle cannot change immediately, but only at a finite rate. Fig. 5 presents the pitch angle controller using a proportional controller.

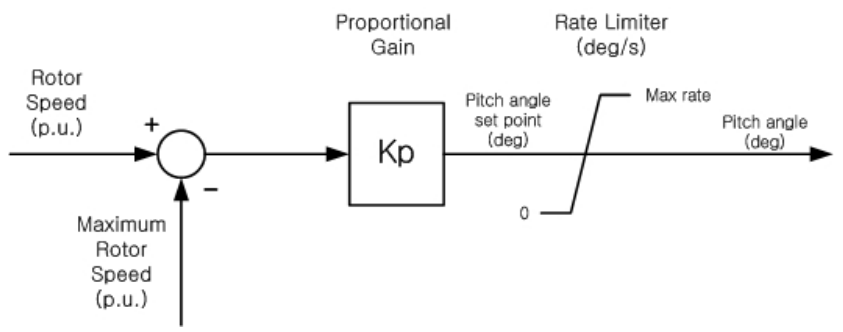

Fig. 5. Pitch Angle Controller.

\section{Case Study}

\subsection{Real-time Simulation Environment}

Fig. 6 shows the block diagram of a real-time simulation environment for a DFIG wind power generation system. The wind speed signal extracted by an anemometer (Product name: 26 SPD) is modified to make an appropriate voltage input signal (Limit: $\pm 10 \mathrm{~V}$ ) for the analog input in the real time simulation environment. In this experiment, a GTAI (Gigabit transceiver Analogue Input) card is used in order to bring in the necessary analog signal into the real time simulation. The DFIG wind power generation system is composed using RSCAD in the workstation. The RTDS and the workstation which are connected over LAN communicate with each other. Using the real-wind speed signal, the real-time simulation of the DFIG wind power generation system is made more realistic.

In this case study, the $2.2 \mathrm{MW}$ rated grid-connected variable speed DFIG wind power generation system is being modeled. The rated, cut-in speed and rated power of the wind turbine drive are $12,6 \mathrm{~m} / \mathrm{s}$, and $2.0 \mathrm{MW}$. The rated voltage of the DFIG and three-phase grid is $0.69,4.16 \mathrm{kV}$ L-L rms. The rated DC-link voltage of the back-to-back PWM converters is $1.58 \mathrm{kV}$. The reference voltage of the
DC-link that the stator-side converter maintains is 1.738 $\mathrm{kV}(1.1 \mathrm{pu})$. The capacity of the reactive power compensated filter is $0.22 \mathrm{Mvar}$. The upper limit of the rotor speed is 1.2 p.u. Figs. 7 and 8 depict the implemented real-time module, wind turbine and DFIG system using RTDS/ RSCAD.

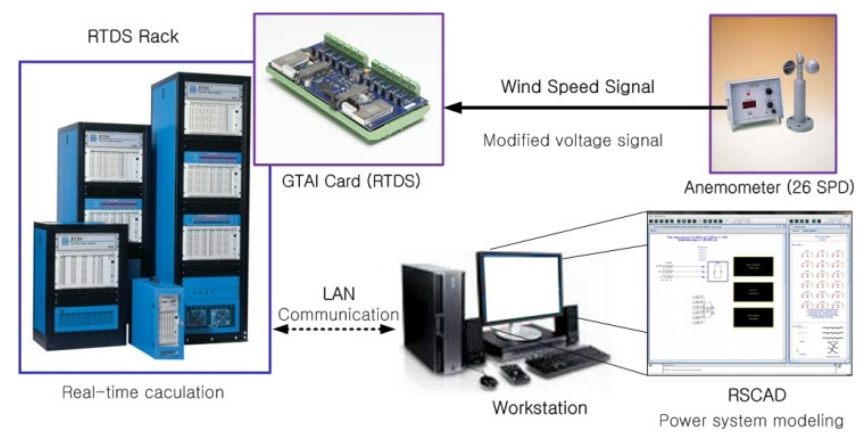

Fig. 6. Real-time Simulation Environment.

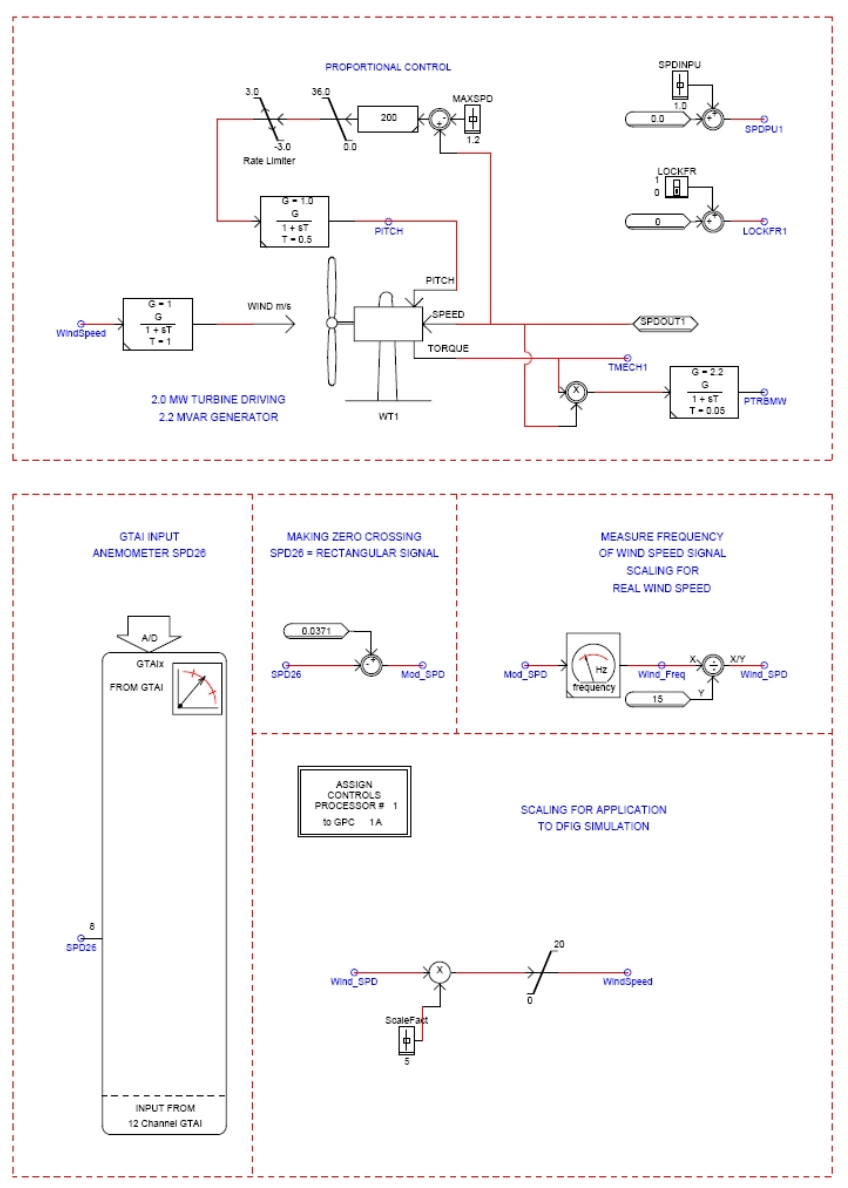

Fig. 7. Wind Turbine and Real-time Signal Module (RSCAD).

\subsection{Pitch Control Simulation}

A variable-speed variable-pitch control strategy is a vital element in commercial wind turbines. In this scheme, the turbine is controlled to operate at a variable speed and 


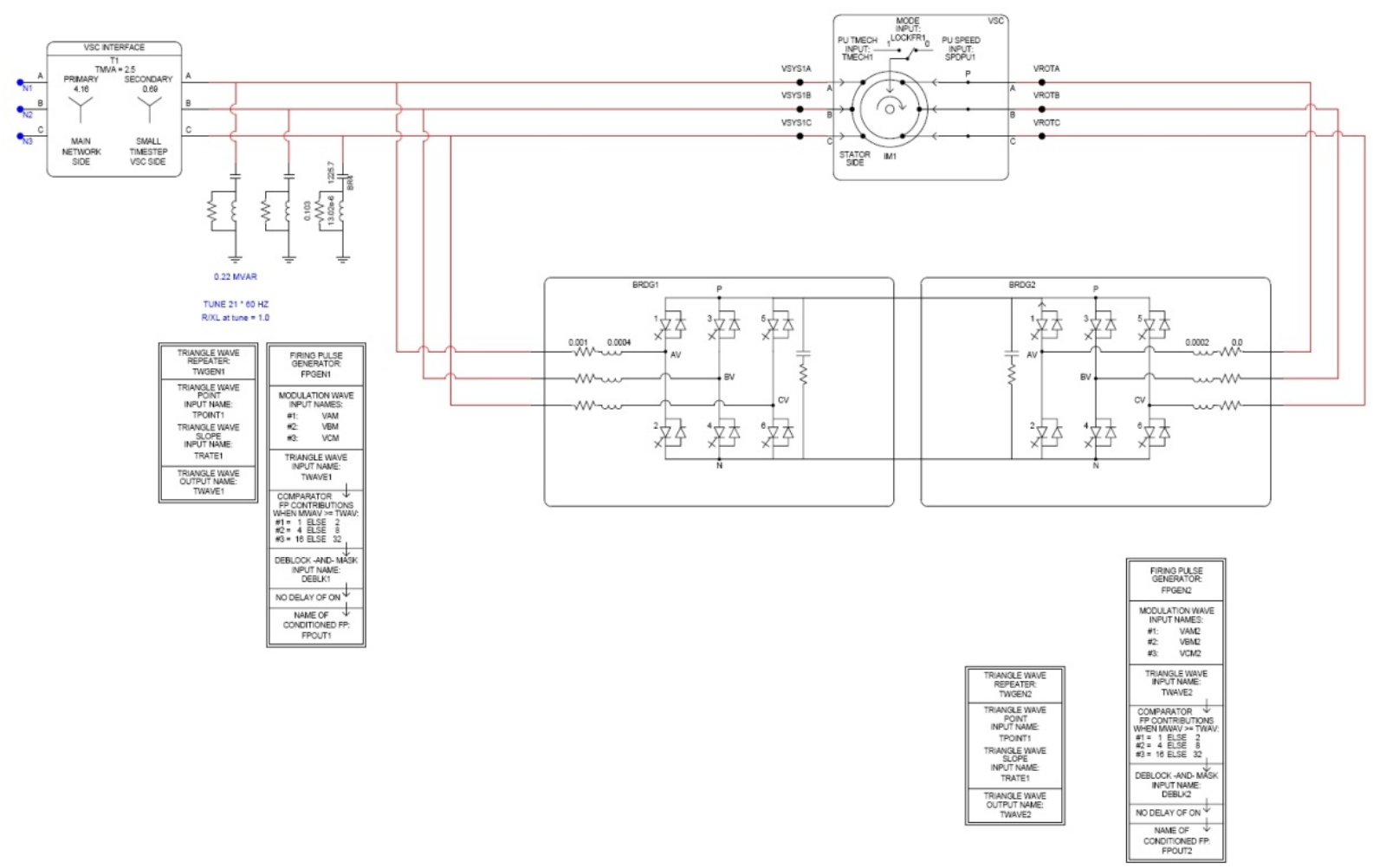

Fig. 8. DFIG System (RSCAD).

fixed pitch below the upper limit of the rotor speed and at a variable pitch above the upper limit. Fig. 9 depicts the variable pitch simulation results of the modeled DFIG. In all graphs, the $\mathrm{x}$-axis component is time (sec). The wind speed is not a real-time input signal, but a programmed signal that increases at a constant rate. The minimum and maximum value of the wind speed is about zero and $20 \mathrm{~m} / \mathrm{s}$.

Fig. 9 (b) shows the rotor speed (p.u.) and generated active power of the DFIG wind power generation system according to the increase of the wind speed. Mechanical torque and active power are not zero because of the initial setting value for the WRIG drive for the stable simulation in RSCAD. In source mode (lock mode), the initial value that distanced it from 1.0 p.u. causes instable initial dynamic behavior (oscillation and divergence) of WRIG.

Therefore, 1.0 p.u. is typically chosen for the initial torque of the wounded rotor. When the wind speed is low, the rotor speed is decreased from 1.0 (initial value in WRIG source mode). Then, the rotor speed is increased by increased torque from the wind turbine when the wind speed is higher than the cut-in speed.

Above the cut-in wind speed, the active power output and rotor speed is increased. Above the upper limit of the rotor speed 1.2 p.u., the pitch angle is increased according to the increase of wind speed to maintain the rotor speed of the DFIG to its constant upper limit. Fig. 9 (b) shows that the rotor speed of a DFIG wind power system is limited, although the wind speed is much higher than its rated wind speed.

Fig. 9 (c) depicts the mechanical torque of the wind turbine drive. Since the DFIG is operated by the mechanical torque of the wind turbine drive, the graphs of the generated active power and mechanical torque are almost identical.

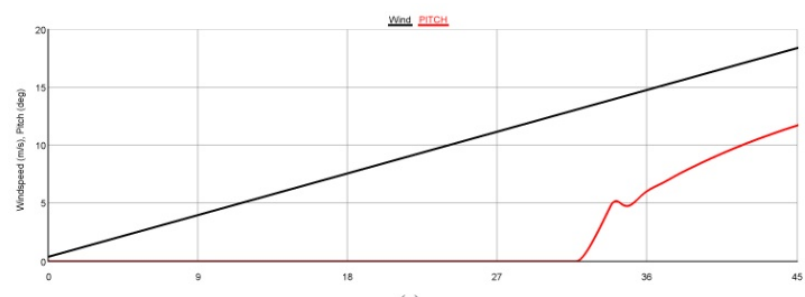

(a)

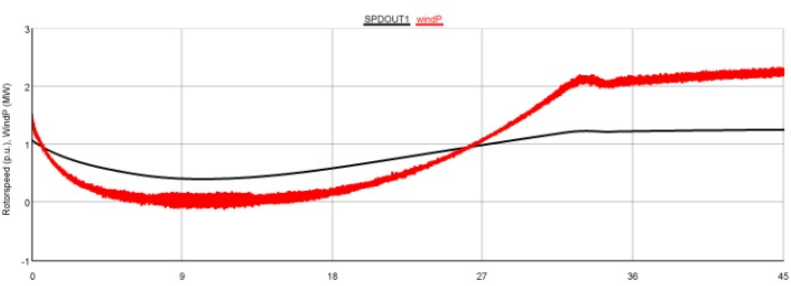

(b)

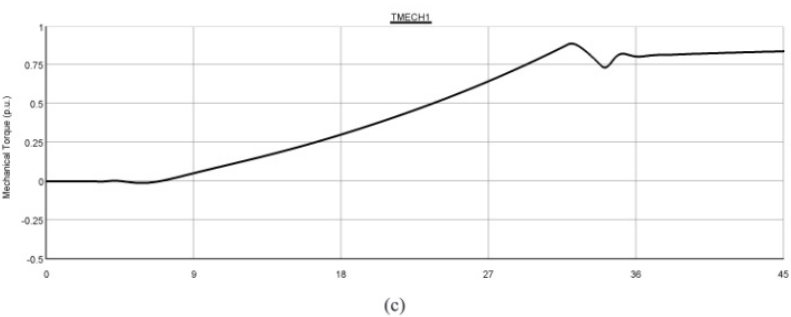

Fig. 9. (a) Programmed Wind Speed \& Pitch, (b) Rotor Speed \& Generated Active power, (c) Mechanical Torque. 


\subsection{Real-wind Speed Simulation}

Since wind speed always fluctuates in real conditions, the implemented system must be exposed to tests with various conditions for realistic and reliable studies. Because the system is sometimes supposed to experience unexpected severe condition, the response of the model, implemented in this paper, the behavior of the model under severe conditions must be analyzed. One of those severe conditions, presented here, has been tested as exploration for such situations.

Fig. 10 (a) shows the pitch change according to the realwind speed variation. In the graph, the wind speed variation range is from $10.5 \mathrm{~m} / \mathrm{s}$ to $17.0 \mathrm{~m} / \mathrm{s}$. When the rotor speed reaches its 1.2 p.u. limit (Fig. 12), the pitch angle is increased by the controller.

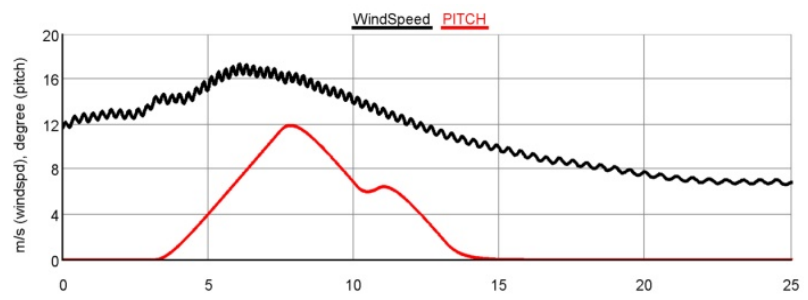

(a)

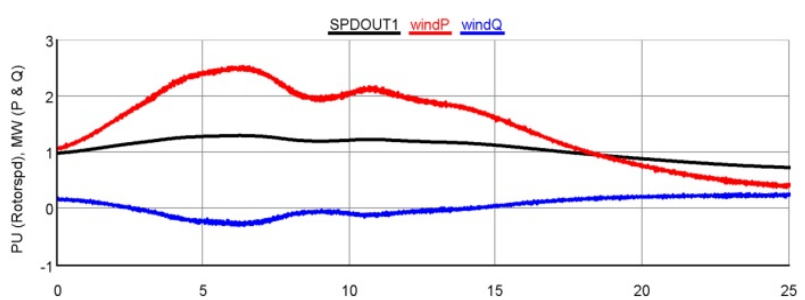

(b)

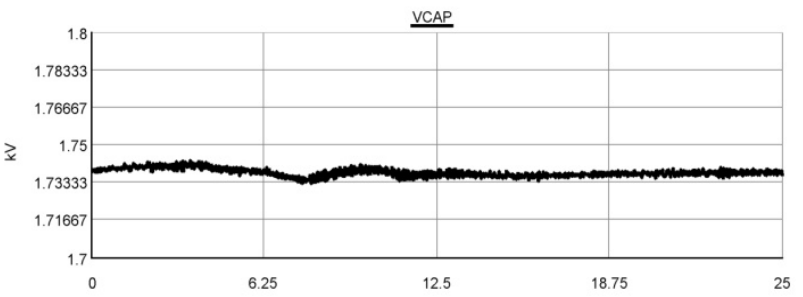

(c)

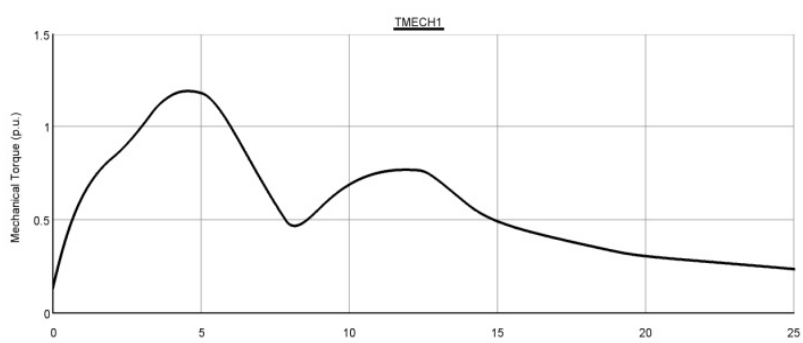

(d)

Fig. 10. (a) Real-Wind Speed \& Pitch, (b) Rotor Speed \& Active Reactive Power, (c) Controlled DC-link Voltage, (d) Mechanical Torque.
Owing to the limited change rate of the pitch angle, the rapid wind speed variation affects the pitch control ability. From $3.0 \mathrm{sec}$ to $6.0 \mathrm{sec}$, wind speed increases suddenly, but the pitch angle change rate is at its maximum value at that time (Fig. 10 (a)). Consequently, the generated active power is over its rated power 2.2 MW for some time (Fig. 10 (b)). However, the rotor speed is limited by the controller. The reactive power is about zero because the stator-side converter controls DC-link voltages and ensures a converter operation at the unity power factor. Fig. 10 (c) shows the controlled DC-link voltage which value is about $1.738 \mathrm{kV}$.

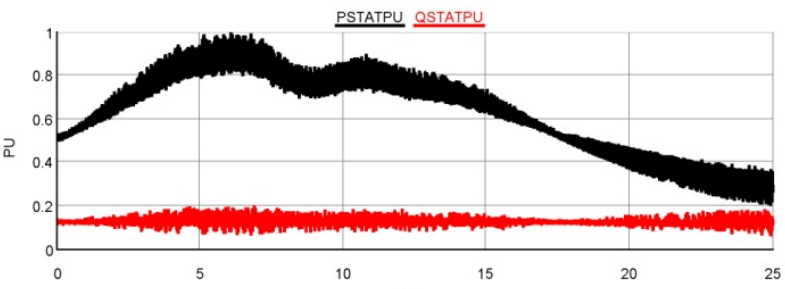

(a)

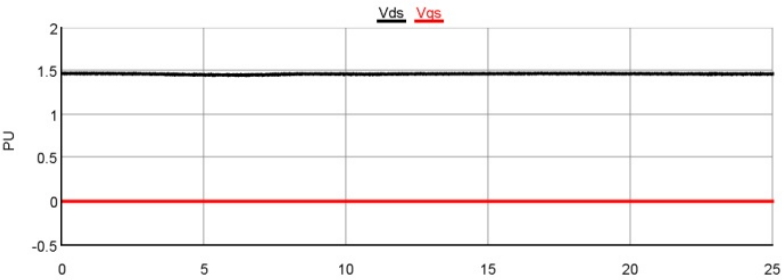

(b)

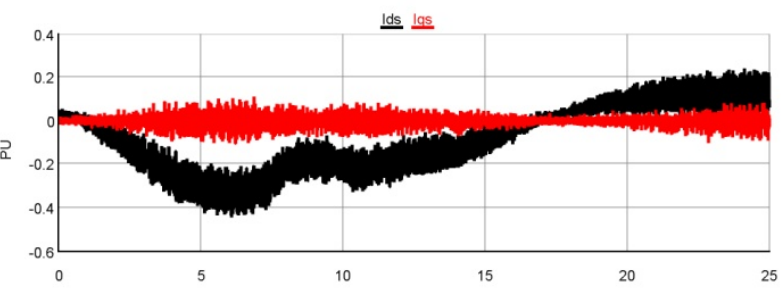

(c)

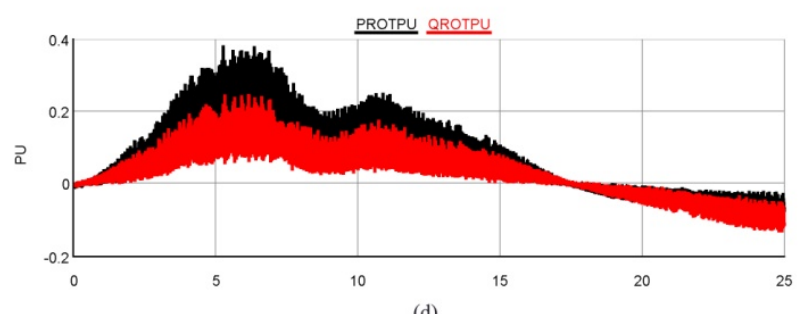

(d)

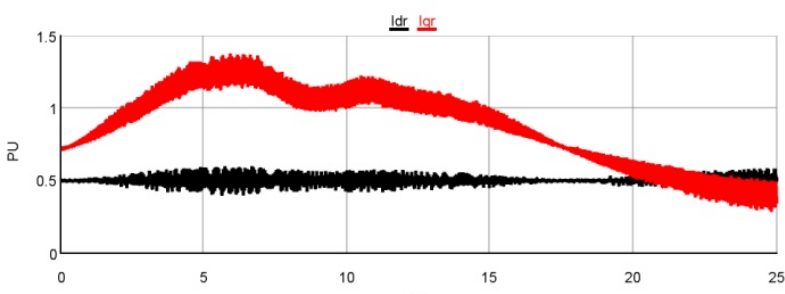

Fig. 11. (a) Stator Active Reactive Generated Power, (b) Stator Voltages (d-q axis), (c) Stator Currents (d-q axis), (d) Rotor Active Reactive Generated Power, (e) Rotor Currents (d-q axis). 
The mechanical torque graph (Fig. $10(\mathrm{~d}))$ is similar to active power graph (Fig. 10 (b)). The pitch angle effects mechanical torque from $4.0 \mathrm{sec}$ to $13.0 \mathrm{sec}$, and brings about active power fluctuation.

In any condition, the stator feeds power into the grid (Fig. 11 (a)). The stator-side converter maintains the reactive power constant. Since the $v_{d s}$ is constant and $v_{q s}$ is zero (Fig. 11 (b)), from Equations (22), (23), the active and reactive power of the stator are determined by $i_{d s}, i_{q s}$ (fig. 11 (c)). The sign of the stator currents are opposite to those of the generated power. The reactive power of the stator would be zero, but the compensated filter affects the value of reactive power.

It can be observed that the rotor of the DFIG generates or absorbs according to the speed of the rotor in Fig. 11 (d). Above the rated rotor speed 1.0 p.u. (Fig. 10 (b)), the DFIG feeds power into the grid. However, the DFIG absorbs power from the grid in the opposite case (from $17.5 \mathrm{sec}$ ).

Since $i_{d r}$ is controlled to be constant, the active and reactive power of the rotor are controlled by $i_{q r}$ (Fig. 11 (e)).

\section{Conclusion}

Several distinctive advantages have made wind power generation systems one of the most attractive options for the future grid. Therefore, the interest of system dynamics including wind power generation systems is increasing rapidly. The real-time simulation supports a more realistic, reliable and accurate study than a non real-time simulation.

In this paper, a $2.2 \mathrm{MW}$ variable speed DFIG wind power generation system is implemented using RTDS/RSCAD. The real-wind speed signal extracted by a real anemometer is connected to the RTDS directly where the real-time simulation is being performed. The stator-flux oriented vector control of the two converters and the pitch control scheme are explained using mathematical representation. In the real-time simulation, the behavior of the model, such as the response of the pitch controller, the voltage of the DC-link and several voltage and current components related to the stator and rotor power, are presented and analyzed in order to prove the validity of the model.

\section{Appendix}

\section{Wind Turbine (RSCAD)}

Rated generator power: 2.2 MVA

Rated turbine power: $2.0 \mathrm{MW}$

Generator speed at rated turbine speed (p.u.): 1.2 p.u.

Rated wind speed: $12.0 \mathrm{~m} / \mathrm{s}$

Cut-in wind speed: $6.0 \mathrm{~m} / \mathrm{s}$

Power coefficient (Type 2 in RSCAD)

$C p(\lambda, \beta)=(0.47-0.0167 \beta) \sin \left(1.57 \frac{\lambda-3 \gamma}{7.5-0.15 \beta}\right)$

$$
\begin{aligned}
& -0.00184 \beta(\lambda-3 \gamma)+0.01 /(1+\lambda) \\
& \gamma=1-\exp \left(-\frac{\lambda}{3}\right)
\end{aligned}
$$

\section{Wounded Rotor Induction Machine (RSCAD)}

Rated MVA: 2.2 MVA

Rated stator voltage (L-L rms): $0.69 \mathrm{kV}$

Turn ratio (rotor over stator): 2.6377

Stator resistance: 0.00462 p.u.

Stator leakage reactance: 0.102 p.u.

Unsaturated magnetizing reactance: 4.348 p.u.

First cage rotor resistance: 0.006 p.u.

First cage rotor leakage reactance: 0.0609 p.u.

Inertia constant: $1.5 \mathrm{MWs} / \mathrm{MVA}$

\section{Acknowledgements}

This work was supported by the National Research Foundation of Korea (NRF) grant funded by the Korea government (MEST) (No. 2009-0083187).

\section{References}

[1] CIGRE Working Group C4. 601, "Technical Brochure on Modeling and Dynamic Behavior of Wind Generation as It Related to Power System Control and Dynamic Performance," CIGRE, Jan. 2007.

[2] Thomas Ackmann (editor), Wind Power in Power Systems, John Wiley \& Sons Ltd, 2005.

[3] Tony Burton, David Sharpe, Nick Jenkins and Ervin Bossanyi, Wind Energy Handbook, John Wiley \& Sons Ltd, 2002.

[4] W. Leonhard, Control of electrical drives, SpringerVerlag, 1985.

[5] S. R. Jones and R. Jones, "A control strategy for sinusoidal supply side convertors," IEE Colloquium on Developments in Real-Time Control for Induction Motor Drives, Digest, pp. 5/1-5/9, Feb. 1993.

[6] R. Pena, G. Asher, J. Clare and R. Cardenas, "A constant frequency constant voltage variable speed stand alone wound rotor induction generator," International Conference on Opportunities and Advances in International Electric Power, pp. 111-114, Mar. 1996.

[7] R. Pena, J. C. Clare and G. M. Asher, "Doubly fed induction generator using back-to-back PWM converters and its application to variable-speed wind energy generation," IEE Proceedings on Electrical Power Applications, Vol.143, No.3, pp. 231-241, May., 1996.

[8] R. Pena, J. C. Clare and G. M. Asher, "A doubly fed induction generator using back-to-back PWM converters supplying an isolated load from a variable speed wind turbine," IEE Proceedings on Electrical Power Applications, Vol.143, No.5, pp.380-387, Sep., 1996. 
[9] S. K. Salman and Babak Badrzadeh, "New Approach for modelling Doubly-Fed Induction Generator (DFIG) for grid-connection studies," European Wind Energy Conference \& Exhibition 2004, Nov., 2004.

[10] R. Cardenas, R. Pena, J. Clare, G. Asher and J. Proboste, "MRAS Observer for Sensorless Control of Standalone Doubly Fed Induction Generators," IEEE Transaction on Energy Conversion, Vol.20, No.4, pp. 710-718, Dec., 2005.

[11] R. Cardenas, R. Pena, J. Clare, G. Asher and J. Proboste, "MRAS Observer for Sensorless Control of Doubly Fed Induction Generators," IEEE Transaction on Power Electronics, Vol.23, No.3, pp.1075-1084, May, 2008.

[12] P. Wheeler, J. Rodriguez, J.C. Clare, L. Empringham, and A. Weinstein, "Matrix converters: a technology review," IEEE Transaction on Industrial Electronics, Vol.49, No.2, pp.276-288, Apr., 2002.

[13] R. Cardenas, R. Pena, G. Tobar, R. Blasco-Gimenez, P. Wheeler, G. Asher and J. Clare, "Analytical and experimental evaluation of a WECS based on a Doubly Fed Induction Generator fed by a matrix converter," IEEE international Symposium on Industrial Electronics, pp.2438-2443, Jun., 2008.

[14] R. Cardenas, R. Pena, P. Wheeler, J. Clare and G. Asher, "Control of the Reactive Power Supplied by a WECS Based on an Induction Generator Fed by a Matrix Converter," IEEE Transaction on Industrial Electronics, Vol.56, No.2, pp.429-438, Feb., 2009.

[15] R. Cardenas, R. Pena, J. Clare and P. Wheeler, "Control of the Reactive Power Supplied by a Matrix Converter," IEEE transaction on Energy conversion, Vol. 24, No.1, pp.301-303, Mar., 2009.

[16] R. Cardenas, R. Pena, G. Tobar, P. Wheeler and G. Asher, "Stability Analysis of a Wind Energy Conversion System Based on a Doubly Fed Induction Generator Fed by a Matrix Converter," IEEE Transaction on Industrial Electronics, Vol.56, No.10, pp.41944206, Oct., 2009.

[17] Real Time Digital Simulator Power System and Control User Manuel, RTDS Technology, Nov., 2006.

[18] I. J. van Vilet, A. M. van Voorden, P. H. Schavemaker, G. C. Paap and L. van der Sluis, "Real-Time Simulation to Study the Impact of Renewable Energy in Power Systems," International Conference on Future Power Systems 2005, pp.1-6, Nov., 2005.

[19] Dae-Jin Park, Young-Ju Kim, Mohd Hasan Ali, Minwon Park and In-Keun Yu, "Modelling of 3MW Wind Power System Generation System Using RTDS," Proceeding of the $38^{\text {th }}$ the KIEE Summer Conference 2007, pp.190-191, Jul., 2007.
[20] Dae-Jin Park, Young-Ju Kim, Mohd Hasan Ali, Minwon Park and In-Keun Yu, "A Novel Real Time Simulation Method for Grid-Connected Wind Generator System by Using RTDS," Proceeding of International Conference on Electrical Machines and Systems 2007, pp.1936-1941, Oct., 2007.

[21] X. Xu, R. De Doncker and D.W. Novotny, "A stator flux oriented induction machine drive," 19th Annual IEEE Power Electronics Specialist Conference, Vol.2, pp.870-876, Apr., 1988.

[22] Prabha Kundur, Power System Stability and Control, McGraw-Hill, 1994.

[23] D. W. Novotny and A. Lipo, Vector Control and Dynamics of AC Drives, Clarendon Press, 1996.

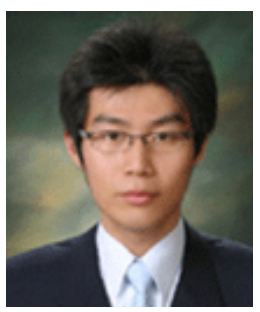

Gilsung Byeon He received his B.S. degree from the School of Electrical Engineering, Korea University, in 2006 $\mathrm{He}$ is now pursuing his Ph.D. at the School of Electrical Engineering, Korea University. His research interests are power system modeling, and control and simulation algorithm analysis.

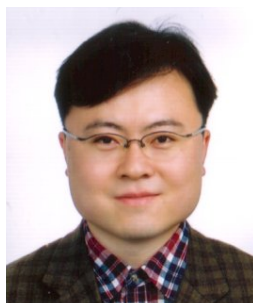

In Kwon Park He received his B.S.E.E. from Yonsei University, South Korea, in 1995 and his M.Sc. from Yonsei University, South Korea, in 1997. After graduation, he worked for LG Industrial Systems from 1997 to 2002. From 2002, he has worked at RTDS Technologies, Inc. His current research interests include real time systems, power system modeling and simulation.

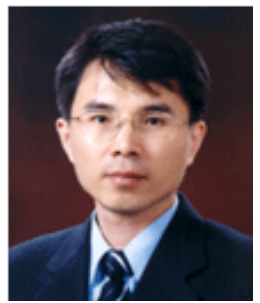

Gilsoo Jang He received his M.S. degree and Ph.D. from Korea University in 1994 and Iowa State University in 1997, respectively. Currently, he is a professor of the School of Electrical Engineering, Korea University. His research interests are power quality and power system control. 